\title{
Plato: A Preservation Planning Tool Integrating Preservation Action Services
}

\author{
Hannes Kulovits, Christoph Becker, Michael Kraxner, Florian Motlik, \\ Kevin Stadler, and Andreas Rauber \\ Vienna University of Technology, Vienna, Austria \\ http://www.ifs.tuwien.ac.at/dp
}

\begin{abstract}
The creation of a concrete plan for preserving a collection of digital objects of a specific institution necessitates the evaluation of available solutions against clearly defined and measurable criteria. This process is called preservation planning and aids in the decision making process to find the most suitable preservation strategy considering the institution's requirements, the planning context and available actions applicable to the objects contained in the repository. Performed manually, this evaluation promises to be hard and tedious work, inasmuch as there exist numerous potential preservation action tools of different quality. In this demonstration, we present Plato 4], an interactive software tool aimed at creating preservation plans.
\end{abstract}

\section{Plato}

The preservation planning tool Plat 11 implements the PLANETS2 Preservation Planning approach 3 which provides an approved way to make informed and accountable decisions on which solution to implement in order to optimally preserve digital objects for a given purpose. The tool is integrated into the PLANETS Interoperability Framework based on open J2EE and web technologies. This environment guarantees loose coupling of services and registries for preservation action and characterisation through flexible discovery and invocation.

For format identification and property extraction, services such as DROID 3 and JHov 4 are used; based on this information, Plato discovers applicable action services such as emulation tools or migration services provided by CRiB [2] through available registries. Comparison and validation of objects as an essential feature of the system maps the specified requirements such as essential object characteristics to measurable criteria that can be compared automatically. Thereby, it considerably improves the repeatability, documentation, and automation of preservation planning.

To not impose any technical restrictions on the user Plato has been developed with very close attention to the web user interface when determining the

\footnotetext{
1 http://www.ifs.tuwien.ac.at/dp/plato

2 http://www.planets-project.eu

3 http://droid.sourceforge.net

4 http://hul.harvard.edu/jhove

B. Christensen-Dalsgaard et al. (Eds.): ECDL 2008, LNCS 5173, pp. 413-414 2008

(C) Springer-Verlag Berlin Heidelberg 2008
} 


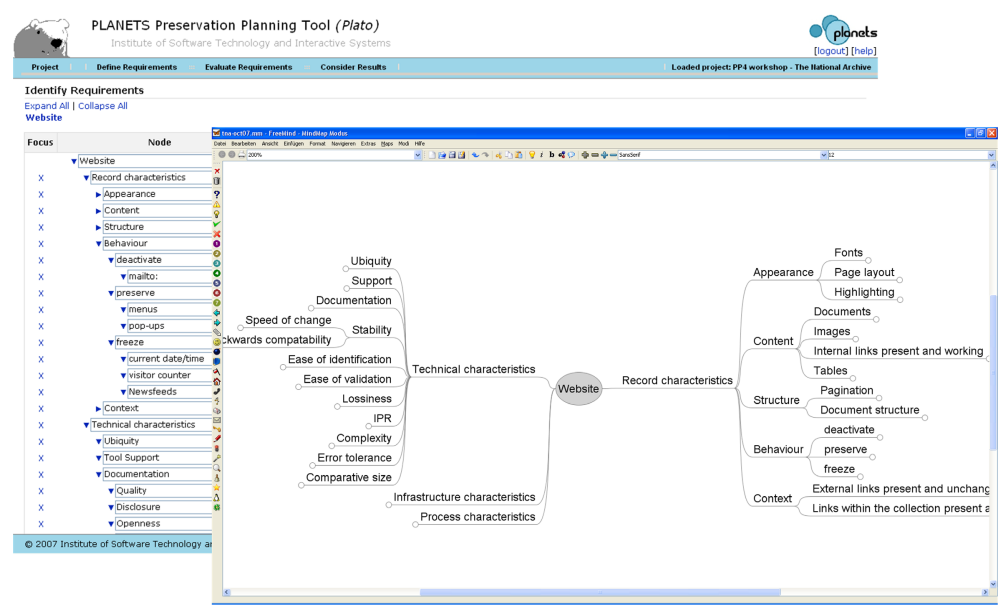

Fig. 1. Requirements tree in Plato

requirements. Figure 1 shows the requirements for a preservation endeavour of a web archive laid out in a tree structure. The tool offers a fully flexible way to enable the specification of a wide range of measurement scales. As the definition of requirements in a tree structure is often done in a workshop setting, Plato also supports tree import from mind-mapping softwares.

The applicability and usefulness of the tool has been validated in a series of workshops and case studies which involved a wide range of institutions [13].

\section{Acknowledgements}

Part of this work was supported by the European Union in FP6, IST, through the PLANETS project, contract 033789.

\section{References}

1. Becker, C., Kolar, G., Kueng, J., Rauber, A.: Preserving interactive multimedia art: A case study in preservation planning. In: Goh, D.H.-L., Cao, T.H., Sølvberg, I.T., Rasmussen, E. (eds.) ICADL 2007. LNCS, vol. 4822, pp. 257-266. Springer, Heidelberg (2007)

2. Ferreira, M., Baptista, A.A., Ramalho, J.C.: An intelligent decision support system for digital preservation. Int. Journal on Digital Libraries (IJDL) 6(4), 295-304 (2007)

3. Strodl, S., Becker, C., Neumayer, R., Rauber, A.: How to choose a digital preservation strategy: Evaluating a preservation planning procedure. In: Proc. JCDL 2007, pp. 29-38 (June 2007)

4. Becker, C., Kulovits, H., Rauber, A., Hofman, H. Plato: A Service Oriented Decision Support System for Preservation Planning. In: Proc. JCDL 2008 (June 2008)

$\sqrt[5]{\text { http://freemind.sourceforge.net }}$ 